\title{
Reseña bibliográfica: Duplá Ansuátegui, A., Dell'Elicine, E., Pérez Mostazo, J. (Eds.) (2018). Antigüedad clásica y naciones modernas en el Viejo y el Nuevo Mundo, Madrid: Ediciones Polifemo, 362 pp.
}

Palabras clave: Antigüedad Clásica; Naciones Modernas; Europa; América; Estudios de Recepción.

Keywords: Classical Antiquity; Modern Nations; Europe; America; Reception Studies.

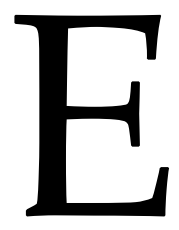

1 presente libro es una compilación de artículos que se proponen analizar la utilización del pasado clásico en la construcción de los discursos identitarios en la modernidad, tanto en Europa como en América. La introducción del libro ya señala que la utilización de ese pasado remite a la necesidad de constituir una suerte de continuidad entre la Antigüedad y las naciones en formación. ${ }^{1}$

El prólogo, “Naciones, historia y ciencias sociales”, escrito por José ÁlvarezJunco, nos presenta un marco teórico general respecto al nacionalismo y su desarrollo como elemento de cohesión social y política. El autor recupera aquí las reconstrucciones del pasado, llevadas a cabo para la configuración de identidades colectivas. Así, la memoria colectiva y la apelación al pasado han sido elementos fundamentales en los procesos de construcción identitaria.

El libro se divide en dos secciones. La primera está dedicada al Viejo Mundo, y en ella encontramos diversos artículos con diferentes temáticas en variados espacios como el español, el francés, el británico y el alemán.

El artículo que abre esta primera sección corresponde a Antonio Duplá Ansuátegui y se titula "Algunas consideraciones sobre la concepción de la historia, la Antigüedad y la nación en la Real Sociedad Bascongada de Amigos del País". En él, el autor se propone analizar la recepción del pasado clásico a través de la concepción de la historia presente en la Real Sociedad Bascongada

\footnotetext{
${ }^{1}$ El tema de la recepción y utilización del pasado clásico en sociedades modernas está siendo objeto de profusa investigación en los últimos años. A modo de ejemplo, podemos citar los libros de Sancho Rocher (2015), Fögen \& Warren (2016) y Stray (2018), todos ellos reseñados en números anteriores de esta revista (Arévalo, 2018; Gómez Britos, 2020; Fernández Roveda, 2020).
} 
de Amigos del País (RSBAP) hacia finales del siglo XVIII, concepción que engloba, entre otros elementos, la idea de la historia como magistra vitae.

El segundo artículo, "Entre Ilerda y Emporion: etnicidad y clasicismo en las raíces del nacionalismo catalán" de Jordi Cortadella, versa sobre la percepción de Grecia y Roma y su impacto sobre el nacionalismo catalán del siglo XIX. En él, se analizan las apelaciones al pasado clásico presentes tanto en las propuestas federalistas de Francesc Pi i Margall y Valentí Almirall como en el llamado "catalanismo tradicionalista" de Josep Torras i Bages y la síntesis de Enric Prat de Riba.

A continuación, encontramos el estudio de Gloria Mora titulado "La arqueología en la construcción de la historia de España: de los viajes anticuarios ilustrados al Catálogo Monumental de España". Aquí, la autora se propone presentar cómo la arqueología fue conformando un discurso en la construcción de las historias de España entre mediados del siglo XVIII y principios del XX. Lo interesante de este trabajo es que muestra cómo la representación del patrimonio material se va constituyendo en España en un discurso independiente del histórico hasta, como señala Mora, "convertirse en testigo absoluto del pasado" (p. 91). De esta forma, se impulsan los estudios arqueológicos por todo el país, creándose instituciones para el desarrollo de la disciplina que no solo tenían la función de llevar a cabo investigaciones, sino también de divulgarlas mediante revistas y series ilustradas.

El cuarto artículo de esta sección, “Viriato en el Congreso de los Diputados: de la Gloriosa a la disolución de las Cortes en España (1868-1939)”, de Pilar Iguácel y Pepa Castillo, se centra en analizar cómo la figura de Viriato fue recuperada como exemplum histórico en el contexto que estudian los autores. La recuperación de Viriato no es aleatoria: el líder lusitano engloba los rasgos más destacables de "lo español", por lo cual se recurre constantemente a él como símbolo de la hispanidad. Viriato constituye, de esta forma, un símbolo de patriotismo, lucha por la libertad y la independencia, debido a su "heroísmo" al enfrentarse contra los romanos en el siglo II a.C. En conclusión, la imagen de Viriato es presentada como la de un héroe cuyas virtudes debían ser imitadas, ya que encajaban con el arquetipo de "lo español" que pretendía construir la España liberal de finales del siglo XIX y comienzos del XX.

El quinto artículo, “La Antigüedad en acción. El sermón sobre la destrucción de la cultura nacional española", realizado por Ignacio Peiró Martín, es el último dedicado exclusivamente a la historia española. En él, se aborda la etapa de destrucción de la historia por parte del franquismo desde 1936, en una suerte de 
guerra cultural, donde colaboraron un número importante de profesionales de la Arqueología y la Historia Antigua.

Grégory Raimond es el autor del sexto trabajo de esta sección, “Arcaísmo y clasicismo en el pensamiento de Pierre Paris: los escultores griegos a la conquista del movimiento". En él, Raimond se propone abordar los pioneros trabajos de Pierre Paris entre finales del siglo XIX y comienzos del XX, relacionados con el origen del arte griego. Lo interesante de este estudio es el análisis de Raimond acerca de cómo el presente de Paris se transparenta en sus trabajos, de manera que se pueden apreciar en sus obras enfoques propios de la época del arqueólogo francés.

A continuación, encontramos el artículo de Martin Linder, "Winning History: Nationalistic Classical Reception in German Board and Card Games from the 'Long 19th Century'”. El autor propone un estudio sobre el uso del pasado clásico en los juegos de cartas y de mesa alemanes desde la Revolución Francesa hasta la Primera Guerra Mundial. Este es un elemento más, aunque poco analizado, de la recepción de la Antigüedad clásica por parte de la cultura alemana del siglo XIX. Linder identifica una tendencia común en los casos abordados de monopolizar y utilizar ciertas partes de la Historia Antigua acorde a la agenda nacionalista alemana.

Richard Hingley es el autor de "Images of Rome: Classical Rome and the United Kingdom, 1880 to 1930 ", en el cual estudia la importancia que tuvieron las representaciones de determinados momentos de la historia romana en el Reino Unido, particularmente en un contexto donde el Imperio Británico estaba atravesando problemas políticos y militares. ${ }^{2}$ De esta forma, en este artículo observamos un análisis sobre la utilidad de las "imágenes de Roma" hacia finales del siglo XIX y comienzos del XX, imágenes relacionadas, justamente, con temáticas militares, políticas, nacionalistas e, incluso, de género.

Cierra esta sección el trabajo de Marta García Morcillo, "Antiquity and Modern Nations in the Liebig Trading Cards", el cual se enfoca en el estudio de los usos de la Historia Antigua por la marca Liebig Extract of Meat Company. El trabajo, centrado en la publicidad de la empresa de industria cárnica, aborda la presencia de temáticas referidas a la Antigüedad clásica en las cartas coleccionables de la empresa, temáticas estrechamente ligadas con los tópicos ideológicos, políticos y económicos presentes en la Europa de finales del siglo XIX. De esta forma, García Morcillo nos revela cómo las cartas coleccionables no

\footnotetext{
${ }^{2}$ Hingley ya ha estudiado previamente la recuperación y utilización del pasado romano en las épocas eduardiana y victoriana. Ver, por ejemplo, Hingley (2000). 
solo tenían una finalidad educativa y de promoción de la empresa, sino que también pretendían promocionar identidades nacionales e ideologías.

La segunda parte del libro se centra específicamente en el Nuevo Mundo y es un recorrido por los usos del pasado clásico desde los nacientes Estados Unidos hasta las repúblicas latinoamericanas.

Clelia Martínez Maza aborda en su artículo "La huella griega en el Senado de los EE.UU." las referencias a modelos políticos del mundo griego clásico en el período revolucionario estadounidense. En la misma línea de algunas de sus investigaciones previas, ${ }^{3}$ la autora expone la recuperación de los modelos políticos griegos de Esparta, Atenas y las Confederaciones, en las disputas entre federalistas y antifederalistas, llevadas a cabo en la Convención de Filadelfia de 1787, ligadas a la organización de los Estados Unidos tras la Guerra de la Independencia.

El siguiente es un trabajo de José M. Portillo Valdés, “Cuando la Antigüedad no puede ser más que moderna. Identidades complejas en el escenario imperial español de finales del siglo XVIII". Este estudio versa sobre las dificultades por las que atravesaron intelectuales de las elites criollas novohispanas para valorizar una antigüedad propia, referida al pasado precolombino en la zona del Virreinato de Nueva España. En este sentido, el autor lleva a cabo un análisis de cómo estas elites letradas llevaron a cabo una reivindicación de ese pasado frente a la distorsionada imagen proveniente de la literatura europea en el marco de la crisis de la monarquía hacia finales del siglo XVIII.

Ricardo del Molino García presenta el tercer título de esta sección, "La Antigüedad clásica y la red protonacional neogranadina (1767-1803)". En él, Molino García se propone estudiar la recepción y utilización de la Antigüedad grecorromana en una etapa previa a la Primera República Colombiana (18101816). De esta forma, el autor analiza cómo el pasado clásico fue apropiado y recepcionado de modo independiente y autónomo, cuestionando la hipótesis de que el pasado grecorromano fuese una mera imitación de las apropiaciones llevadas a cabo en los procesos revolucionarios estadounidenses y franceses. Así, en este artículo encontramos apelaciones a la Antigüedad clásica por parte tanto de defensores de la monarquía hispana, como de los primeros intelectuales independentistas.

Cierra esta sección el estudio de Eleonora Dell’Elicine titulado “Pasado clásico y nación moderna: los usos de la Antigüedad en la construcción de un proyecto

\footnotetext{
${ }^{3}$ Martínez Maza (2013).

Anuario de la Escuela de Historia Virtual - Año 11 - No 18 - 2020: pp. 262-267. ISSN: 1853-7049
} 
político para la Nación Argentina (1837-1852)". En consonancia con los trabajos previos de esta parte del libro, la autora aborda la utilización del pasado clásico en el proceso de conformación de las naciones hispanoamericanas, en este caso la Argentina, a partir de dos momentos. En el primero, se aboca al análisis de la recepción de la historia grecorromana como magistra vitae para los revolucionarios de mayo. En el segundo, la autora se centra en cómo la literatura romántica de la Generación del '37 entiende al pasado clásico como algo que simplemente necesita ser explicado y como algo que debe funcionar como guía de acción para el presente a través de la imitación.

Varias conclusiones se desprenden de la lectura de este libro. En primer lugar, la miríada de temáticas aquí abordadas permite enriquecer el campo de estudios sobre la recepción y utilización del pasado clásico en las sociedades modernas. La pluralidad de temas, de esta forma, favorece la observación de cómo el pasado grecorromano es retomado y utilizado a través de diversos mecanismos. En

segundo lugar, y ligado a lo anterior, los trabajos aquí presentados, aunque no se han enfocado en el análisis de fuentes literarias, destacan de todos modos por la amplia variedad de fuentes estudiadas: arqueológicas, materiales y visuales. En tercer lugar, un punto fuerte de este libro es que no se ha centrado exclusivamente en Europa occidental o en Estados Unidos -algo muy común en este tipo de investigaciones-, sino que ha incluido estudios referentes a la apropiación de la Antigüedad clásica en las nacientes repúblicas hispanoamericanas: México, Colombia y Argentina. Por todo esto, el libro es un interesante aporte a los estudios sobre historiografía moderna de la Historia Antigua.

\section{Referencias bibliográficas}

Arévalo, M. (2018). Reseña bibliográfica de: “Sancho Rocher, L. (Coord.) (2015). La Antigüedad como paradigma. Espejismos, mitos y silencios en el uso de la historia del mundo clásico por los modernos. Zaragoza: Prensas de la Universidad de Zaragoza. 334 pp." Anuario de la Escuela de Historia Virtual, 14, 132-136.

Fernández Roveda, L. N. (2020): Reseña bibliográfica de: “Stray, C. (2018). Classics in Britain: Scholarship, Education, and Publishing 1800-2000. Oxford: Oxford University Press. Xxvi, 385 pp." Anuario de la Escuela de Historia Virtual, $17,145-149$. 
Gómez Britos, M. L. (2020): Reseña bibliográfica de: “Fögen, T. y Warren, R. (Eds.) (2016). Graeco-Roman Antiquity and the Idea of Nationalism in the 19th Century. Case Studies. Berlin; Boston: Walter de Gruyter. Vii, 305 pp." Anuario de la Escuela de Historia Virtual, 17, 154-157.

Hingley, R. (2000). Roman officers and English gentlemen. Londres: Routledge.

Martínez Maza, C. (2013). El espejo griego: Esparta, Atenas y las ligas griegas en la América del período constituyente (1786-1789). Barcelona: Bellaterra.

Sancho Rocher, L. (Ed.) (2015). La Antigüedad como paradigma. Espejismos, mitos y silencios en el uso de la historia del mundo clásico por los modernos. Zaragoza: Prensas de la Universidad de Zaragoza.

Mauro Gabriel Arévalo Universidad Nacional de Córdoba, Argentina mauro.gabrielarevalo@gmail.com

Para citar este artículo:

Arévalo, Mauro Gabriel (2020). Reseña bibliográfica: “Duplá Ansuátegui, A., Dell'Elicine, E., Pérez Mostazo, J. (Eds.) (2018). Antigüedad clásica y naciones modernas en el Viejo y el Nuevo Mundo, Madrid: Ediciones Polifemo, 362 pp." Anuario de la Escuela de Historia Virtual, 18, 262-267. 